\title{
The influence of a cognitive behavioural approach on changing patient expectations for conservative care in shoulder pain treatment: a protocol for a pragmatic randomized controlled trial
}

Heather Myers ${ }^{1 *}$, Francis Keefe ${ }^{2}$, Steven Z. George ${ }^{3}$, June Kennedy ${ }^{1}$, Ashley Davis Lake ${ }^{1}$, Corina Martinez ${ }^{1}$ and Chad Cook ${ }^{4}$

\begin{abstract}
Background: Despite similar outcomes for surgery and conservative care, the number of surgeries to treat rotator cuff related shoulder pain has increased. Interventions designed to enhance treatment expectations for conservative care have been shown to improve patient expectations, but no studies have yet explored whether such interventions influence patient decisions to pursue surgery. The purpose of this randomized clinical trial is to examine the effect of an intervention designed to improve expectations of conservative care on the decision to have surgery.

Methods: We will test the effectiveness of the Patient Engagement, Education, and Restructuring of Cognitions (PEERC) intervention which is intended to change expectations regarding conservative care. The PEERC intervention will be evaluated in a randomized, pragmatic "add-on" trial, to better understand the effect the intervention has on outcomes. Ninety-four (94) participants with rotator cuff related shoulder pain referred for physical therapy will be randomized to receive either impairment-based care or impairment-based care plus PEERC. Both groups will receive impairment-based conservative treatment created by compiling the evidence associated with established, effective interventions. Participants assigned to the impairment-based care plus PEERC condition will also receive the PEERC intervention. This intervention, informed by principles of cognitive behavioral therapy, involves three components: (1) strategies to enhance engagement, (2) education and (3) cognitive restructuring and behavioral activation. Outcomes will be assessed at multiple points between enrolment and six months after discharge. The primary outcome is patient reported decision to have surgery and the secondary outcomes are pain, function, expectations and satisfaction with conservative care.
\end{abstract}

* Correspondence: heather.myers@duke.edu

'Physical Therapist, Urbaniak Sports Sciences Institute, Duke University Health System, 3475 Erwin Rd, Durham, NC 27705, USA

Full list of author information is available at the end of the article

C C The Author(s). 2021 Open Access This article is licensed under a Creative Commons Attribution 4.0 International License, which permits use, sharing, adaptation, distribution and reproduction in any medium or format, as long as you give appropriate credit to the original author(s) and the source, provide a link to the Creative Commons licence, and indicate if changes were made. The images or other third party material in this article are included in the article's Creative Commons licence, unless indicated otherwise in a credit line to the material. If material is not included in the article's Creative Commons licence and your intended use is not permitted by statutory regulation or exceeds the permitted use, you will need to obtain permission directly from the copyright holder. To view a copy of this licence, visit http://creativecommons.org/licenses/by/4.0/. The Creative Commons Public Domain Dedication waiver (http://creativecommons.org/publicdomain/zero/1.0/) applies to the data made available in this article, unless otherwise stated in a credit line to the data. 
Discussion: Rotator cuff related shoulder pain is highly prevalent, and because conservative and surgical treatments have similar outcomes, an intervention that changes expectations about conservative care could alter patient reports of their decision to have surgery and ultimately could lead to lower healthcare costs and decreased risk of surgical complications.

Trial registration: This study is registered as NCT03353272 at ClincialTrials.gov.

Keywords: Rotator Cuff, Shoulder, Cognitive Behavioral Therapy, Expectations

\section{Background}

In comparative trials involving rotator cuff related shoulder pain (RCRSP), conservative interventions have yielded comparable outcomes with surgery [1-4]. However, despite the greater risks of harms, higher costs, and a high percentage of re-tears associated with a surgical approach, the number of shoulder surgeries for all forms of RCRSP pain continues to escalate [5-7]. In patients with RCRSP, pre-treatment expectations of the success of surgical and/or conservative approaches have demonstrated strong relationships with post-treatment outcomes [8-10]. The shoulder is not unique in these associations as patient expectations are known to influence treatment outcomes for cervical, low back and lower extremity disorders as well [11-14].

Patient expectations are beliefs or attitudes that include pre-treatment thoughts and beliefs regarding the need for specific treatment methods and the timing and intensity of these methods. Brief interventions designed to alter and enhance treatment expectations for conservative treatment appear to result in slight improvements in expectations $[15,16]$, but not outcomes. The few interventions that have been tested have methodological problems including the failure to attend to issues of treatment fidelity and reliance on overly simplistic methods for altering expectations such as a patient handout or a one-time educational program $[15,16]$.

To date, no studies have explored whether a cognitivebehavioral intervention can influence patient reports of their decision to pursue surgery. We posit that previous approaches to change patient expectations have had only modest effects because they do not include theory-based treatment techniques known to influence patient beliefs. Our study purpose is to test an innovative intervention to alter expectations about conservative care that is informed by principles of cognitive-behavioral theory: Patient Engagement, Education, and Restructuring of Cognitions (PEERC). The cognitive-behavioral therapy (CBT) treatment techniques that form the core of our PEERC intervention are patient-centered and are designed not only to alter expectations but also decisions to pursue surgical treatment.

\section{Primary and Secondary Objectives}

The purpose of this randomized clinical trial is to examine the effect of PEERC, an intervention designed to improve expectations of conservative care, on the patient reports of their decision to have versus not have surgery (primary outcome). Our secondary aim is to evaluate the impact of PEERC on pain, function, expectations and satisfaction with conservative care (secondary).

\section{Trial Design}

The study design is a randomized, pragmatic, "addon" clinical trial. Pragmatic trials optimize normal everyday care processes and are designed to show the 'real-world' effectiveness of an intervention in broad patient groups. The PRagmatic-Explanatory Continuum Indicator Summary 2 (PRECIS-2) is a tool to gauge if the study design matches the intended purpose by rating nine domains on a continuum from very explanatory (ideal conditions) to very pragmatic (usual care conditions) (ICC >0.67) $[17,18]$. Fig. 1 illustrates the continuum for the PEERC trial based on input from the study team. Add-on trials are appropriate when an experimental intervention is tested on participants with a condition in which an established, effective treatment is present. In "add-on" trials, all participants (in both conditions) receive an established, effective treatment. Add-on designs are especially useful for testing of experimental interventions with mechanisms of action different from that of the established, effective treatment [19]. Add-on trials allow the investigators to better understand the isolated 'effect' of the "add-on" intervention [20]. In this study, the PEERC intervention will be the "add-on" component to the established impairment-based physical therapy treatment. Planning for this study was initiated in 2017 and continues with enrolment. This study protocol is described using both the SPIRIT [21, 22] guideline for the minimum content of a clinical trial protocol and the CONSORT Statement and Checklist [21] for reporting in clinical trials to facilitate complete reporting. The TIDieR [22] guidelines were followed when describing the study interventions. Figure 2 illustrates the flow of enrolment, allocation, and follow up. The trial is registered on ClinicalTrials.gov: NCT03353272. 


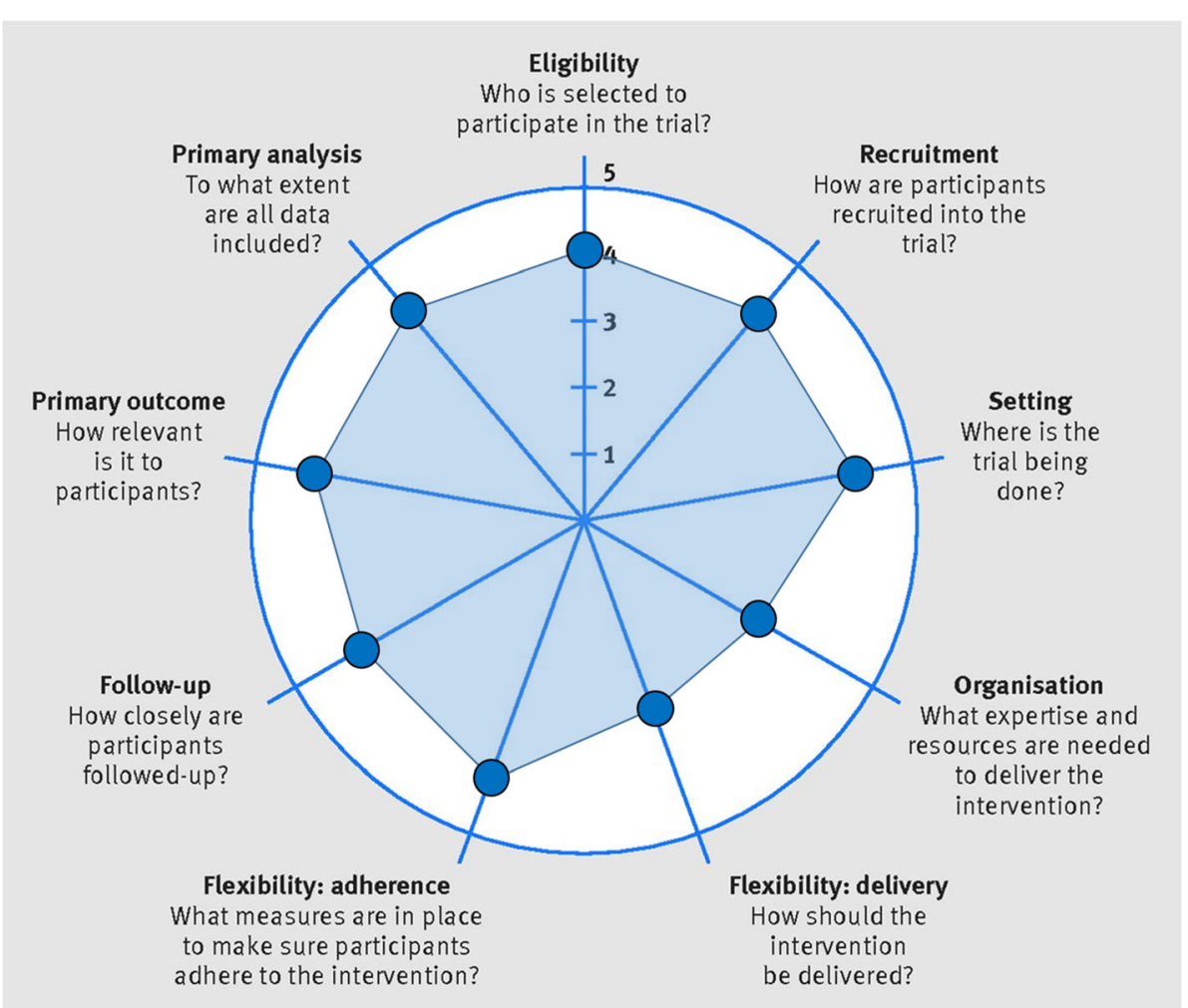

Fig. 1 The PRagmatic-Explanatory Continuum Indicator Summary 2 (PRECIS-2) wheel [17]

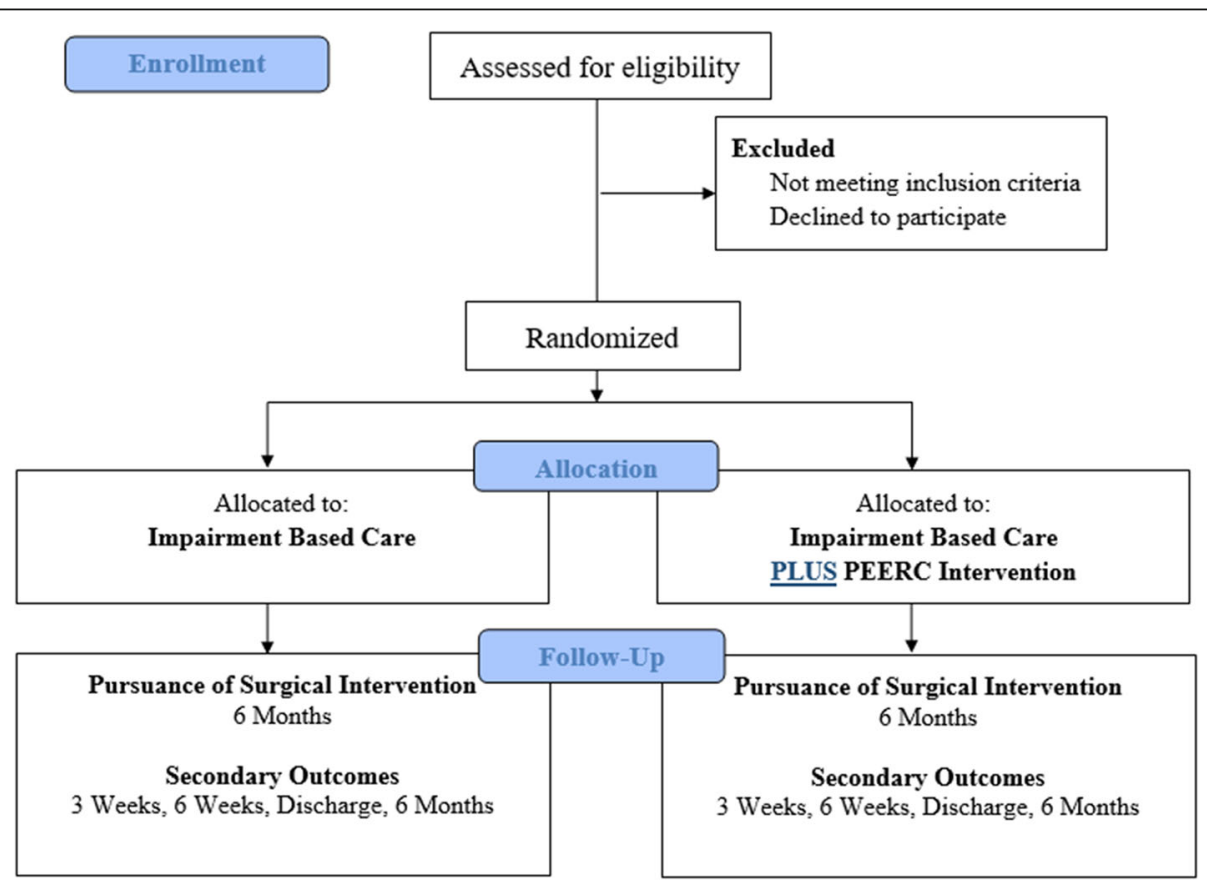

Fig. 2 CONSORT Flow diagram for enrolment, allocation, and follow up 


\section{Methods}

\section{Recruitment and Consent}

Consecutive patients with RCRSP referred by primary care physicians, orthopaedic surgeons, and physician assistants for physical therapy are recruited for the trial. RCRSP diagnoses include conditions such as subacromial pain (impingement) syndrome, rotator cuff tendinopathy, and symptomatic partial and full thickness rotator cuff tears. The informed consent process is performed by institutionally-trained research personnel. Study activities are not initiated until after the patient provides written consent.

\section{Setting}

All patients are treated at Duke Sports Physical Therapy at the James R. Urbaniak, MD Sports Sciences Institute at Duke University located in Durham, North Carolina, United States. This clinic employs over 30 physical therapists, the majority having advanced specialization in musculoskeletal-based disorders and experience participating in clinical trials. Several physicians, both primary care physicians and orthopaedic surgeons, from the James R. Urbaniak, MD, Sports Sciences Institute, who specialize in management of shoulder conditions, refer patients directly to this hospital-based outpatient physical therapy clinic.

\section{Inclusion and Exclusion Criteria}

Inclusion criteria for this protocol include: ages 18 to 70; a mobile or land-line telephone; the ability to read, write, and speak English; and an RCRSP diagnosis inclusive of both acute and chronic cases for which the date of onset will be recorded. We exclude patients who have received, or are scheduled for, a surgical intervention for their shoulder condition, demonstrate any evidence of cervicogenic pain and/or radiculopathy from cervical origin, or who demonstrate symptoms consistent with thoracic outlet syndrome; all of which will be identified during the clinical examinations by the attending physician and physical therapist. We also exclude individuals who are undergoing treatment for a serious psychological disorder (e.g., severe depression, psychosis).

\section{Randomization and Blinding}

Consented participants are randomized to receive either the (1) impairment based care group or (2) impairment based care plus PEERC group (Fig. 2). Consecutively numbered, sealed, opaque envelopes containing group allocation were prepared by a researcher with no other involvement in the study. Condition allocation involves randomization within random permuted blocks using the random number function in Excel and is stratified according to treating therapist so that all physical therapists will deliver approximately equal numbers of patients in both conditions to control for therapist variation. Participants are blinded to study purpose of improving expectations of conservative care and decisions to pursue surgery. Rather than employ deceit, it is communicated that the investigators wish to improve the patient experience through additional education and interaction.

\section{Interventions}

Both groups receive a dedicated impairment-based, physical therapy approach that is performed in the same clinic.

Impairment-based care- The impairment based care is pragmatic, but involves an established, three step phased approach supported by Kuhn [23], Garrison [24], and Stevenson [25]. The three phases include an inflammatory phase, a subacute/early strengthening phase, and an advanced strengthening phase. Patients move from one phase to another based on report of pain and mastery of the activities within the current phase. The home exercise program of the phased approach will be standardized but the dosage of the clinical interventions will be specific to the examination findings. The phased approach allows patient-centred care that is unique to the needs of the patient and his/her progress, but reduces the variability of care that is common in physical therapy settings. Table 1 outlines the staging criteria, goals, and sample exercises of the three phases used in this protocol. Subsequent visit frequency and duration is determined pragmatically by the evaluating physical therapist and may be adjusted in response to progress toward goals. This evaluating therapist is considered the primary therapist, with a secondary physical therapist providing care in the event that the primary therapist is unavailable. No participant is treated by more than two different therapists over the course of his or her care. Participants who have received a corticosteroid injection for rotator cuff related shoulder pain will not be excluded, nor will subsequent concomitant use of injection be cause for withdrawal from the study. Corticosteroid injections, along with the date of the injection, will be recorded in the participant's study record and in the study database. Oral NSAIDS will also be permitted at the patient's discretion. In the absence of extenuating circumstances, patients are discharged from care when all goals (see Table 1) of each treatment phase are met.

PEERC Intervention- All patients in this condition receive the care outlined above for the impairment-based care condition. In addition, they receive a telephonebased intervention (PEERC), designed by the authors, to challenge and change underlying thoughts, beliefs, and attitudes related to treatment expectations regarding conservative care. PEERC, based on cognitivebehavioural principles, is delivered by one of two 
Table 1 Phased Criteria for Progression of Therapeutic Exercise

Phase I: Weeks 0-2

No activities that cause pain $>3 / 10$.
Goal: Decrease inflammation and pain

Goal: Improve glenohumeral and

scapulothoracic ROM

Goal: Address soft tissue restriction as it relates to postural positioning (i.e. Pectoralis Minor and Posterior Capsule)

Goal: Improve scapular neuromuscular control

Goal: full pain free AROM in all planes with good mechanics

Goal: Increase strength/motor control of scapular and rotator cuff muscles for active use of arm

\section{positions.}

Closed chain exercises, resistance exercises below 90 degrees elevation, and stabilization exercises.
Phase III: Weeks 6-8

Education to perform functional exercises maintaining postural awareness and scapular stabilization. Advance rotator cuff and scapular strengthening exercises.
Goal: Normalize rotator cuff and scapular strengthening; restore pattern-generated movements

Goal: maintenance of posture and alignment to become subconscious

Goal: Integrate kinetic chain activities pertinent to sport/work demands Goal: Return to normal function with ADLs and recreational activities
Sample activities may include: PROM and/or AAROM activities to address range of motion deficits; Pectoralis Minor stretch on foam roll, cross body adduction stretch, thoracic mobilization on foam roll, postural corrective exercises, scapular setting with ROM activities in supine and progressing to standing; resisted scapular retraction; resisted scapular depression; resisted serratus anterior activities

Criteria to progress to Phase II:

- Demonstration of proper postural alignment with scapular setting - minimal upper trap activation, no scapular winging, or, if winging is present it must be asymptomatic with negative retraction and assistance tests

- Able to achieve full pain free passive flexion in supine.

- $80 \%$ active flexion against gravity

- worst pain 5/10 or less during normal ADLs

Sample activities may include: 90/90 Pectoralis Minor stretch, sleeper stretch, AROM activities with focus on proper movement pattern; prone mid trap and lower trap strengthening; resisted periscapular strengthening; resisted rotator cuff strengthening below shoulder height; closed chain stabilization activities with progressive weight bearing as long as scapula is stable and not winging under load.

\section{Criteria to progress to Phase III:}

- full pain free AROM shoulder flexion with symmetric mechanics and no or asymptomatic scapular dyskinesia

- 5/5 MMT of scapular and rotator cuff musculature or within $10 \%$ of uninvolved upper extremity as measured with $\mathrm{HHD}$

Sample activities may include: strengthening and stabilization activities above 90 degrees; diagonal patterns; dynamic activities to improve performance during functional and/or athletic tasks; core, balance, and endurance activities needed for work/sport

\section{Criteria for discharge:}

- Maintain full and pain-free AROM in all planes in seated or standing position with good mechanics (no or asymptomatic scapular dyskinesia)

- Demonstration of 5/5 MMT or $10 \%$ margin as measured with HHD for shoulder flexion, abduction, rotator cuff, scapular stabilizing muscles

- MCIDDIC of outcome measures will demonstrate significant change in function

- Patient demonstrates independence with home exercise program and strategies for self-management of symptom resolution should they arise

ROM Range of Motion, AROM Active Range of Motion, PROM Passive Range of Motion, ADL Activity of Daily Living, MMT Manual Muscle Test, HHD Hand Held Dynamometry, MCID Minimally Clinical Important Difference

specifically trained physical therapists who conduct six 30-minute telephone sessions with participants over a six-week period beginning the second week of physical therapy participation. Treatment techniques used in PEERC are drawn from CBT to address issues related to thought distortions and irrational beliefs common in patients who have RCRSP. These techniques, summarized in Table 2, are grouped into three domains: engagement, education and cognitive structuring.

\section{Outcome Collection}

Outcomes of interest are collected by study personnel at the time of consent, after 3 weeks of intervention, after 6 weeks of intervention, at discharge, and at 6 months following discharge. With the exception of the final time point, these measures are collected in person. Table 3 illustrates the schedule of enrolment, interventions, and assessments.

\section{Primary Outcome}

Our primary outcome measure is patient report of the decision to pursue surgery. Since the "add on" intervention of our study included patient decision-making support options, education, and facts that were designed to influence expectations, we were interested in whether this approach truly influenced high-stakes patient 
Table 2 Components and Defining Elements of the PEERC Intervention

\begin{tabular}{ll}
\hline PEERC Component & Defining Elements of the PEERC Intervention \\
\hline Patient & $\begin{array}{l}\text { The engagement approach uses motivational interviewing (a method that works on facilitating and engaging intrinsic } \\
\text { motivation within the client in order to change behavior) and elicitation of thoughts and beliefs about the patient's targeted } \\
\text { expectations. The physical therapist uses behavioral interviewing methods to elicit information on thoughts, feelings, and } \\
\text { behavior related to pain. The interaction focuses on the patients' pain, how pain influences their lives, and their thoughts and } \\
\text { beliefs about pain. }\end{array}$ \\
Education & $\begin{array}{l}\text { The health coach emphasizes that pain is a complex, multidimensional experience that is affected by thoughts, feelings and } \\
\text { behaviors as well as the important role that self-management plays in treatment. Educational methods are informed by the lit- } \\
\text { erature on health literacy and use simple diagrams and charts from a provided booklet to help patients understand the }\end{array}$ \\
& $\begin{array}{l}\text { equivocal results of conservative and non-conservative interventions. The health coach also familiarizes patients with the } \\
\text { current most recommended strategies for care, including any potential harms, a timeline of expectancy and recurrence rates. }\end{array}$ \\
Regnitive & $\begin{array}{l}\text { Cognitive restructuring involves learning how: (1) to recognize thoughts that are distorted, unrealistic and/or self-defeating; (2) } \\
\text { to replace these thoughts with more rational, realistic, adaptive thinking [26]; and (3) to engage in behavioral activation as- } \\
\text { signments designed to reinforce more adaptive thinking. Home based strategies such as behaviorally testing negative } \\
\text { thoughts via behavioral activation exercises (e.g. engaging in an activity the patient is capable of, but has been avoiding be- } \\
\text { cause of fear of pain) are assigned. A number of CBT methods are employed, including discussion of how thoughts, feelings, } \\
\text { and actions affect and are affected by pain, and a review of prior session content and practices. The patient is encouraged to } \\
\text { identify activities that the user tends to avoid, leading to discussions of how to change activities and the development of an } \\
\text { individual plan to increase the fit between daily activities and personal goals. }\end{array}$
\end{tabular}

decisions, such as pursuance of surgery. Prior surgical decision-making studies have used similar or Likertbased outcomes $[27,28]$. We selected a question framed around the patient's choice among treatment approaches, and included the binary question: "Have you had surgery or are you scheduled for surgery for the shoulder problem that you were treated for in physical therapy?" We will use telephone contact at 6 months after discharge from impairment-based care. Because patients may pursue surgery outside of the study institution, in which case a scheduled procedure would not be documented in the medical record, this direct contact will better serve to capture decision of surgical pursuance.

\section{Secondary Outcomes}

Secondary outcome measures include changes pain, function, expectations and satisfaction with conservative care. The construct of pain is assessed through the Shoulder Pain and Disability Index (SPADI) [29-32] and the Numeric Pain Rating Scale (NPRS) [33-35]. Functional constructs are measured with the SPADI, Tegner Activity Scale (TEGNER) [36], Single Assessment Numeric Evaluation (SANE) [37-39], and the Global Rating of Change (GRoC) [40-45] score. Expectations and satisfaction are measured with the MODEMS-E and MODEMS-S questionnaires respectively. The MODEMS $[26,46,47]$ is a set of musculoskeletal assessment instruments created by the American Academy of Orthopaedic Surgeons.

Expectations - The MODEMS expectations scale (MODEMS-E) is a six-item instrument designed to capture patient expectations across a wide range of musculoskeletal conditions. The MODEMS-E patient expectation scale has been used by a number of studies and has shown validity in predicting outcomes in conservative and surgical interventions. The instrument is a Likert-based scoring tool with a mean score of 5 out of 5 (indicating high expectations of positive outcomes) and a mean score of 1 out of 5 (indicating very poor expectations of positive outcomes) [46].

Satisfaction - Patient satisfaction with the conservative care received in our clinic will be measured using the MODEMS-S. The MODEMS $-\mathrm{S}$ consists of five similar stated questions from the MODEMS-E, but the questions are written to assess whether one's expectations were met. The MODEMS-S instrument is also a Likertbased scoring tool with a mean score of 1 out of 5 (indicating expectations were met) and a mean score of 5 out of 5 (indicating expectations were not met) [46]. Table 4 details further description and the psychometric properties of each patient reported outcome included in the study.

\section{Patient Demographics and Characteristics}

To describe patient demographics and presentation, we will report age, sex, education level, work status, marital status, referral source (primary care physician or orthopaedist), history of corticosteroid injection for the current episode, and prior participation in physical therapy for same or different diagnosis. Instruments to assess systemic and comorbidities include the Optimal Screening for Prediction of Referral and Outcome- Review of Systems (OSPRO-ROS) [48] and the Pain Catastrophizing Scale (PCS) [50, 51]. The OSPRO-ROS is a review-of-systems screening tool that includes constructs associated with comorbidities and systemic pathologies [55]. The PCS is a 12 item questionnaire ranking types of thoughts and feelings one has while in pain from 0 (not at all) to 4 (all the time) [50]. Table 4 details the psychometric properties of the OSPRO-ROS and PCS. 
Table 3 Schedule of enrolment, interventions, and assessments

\begin{tabular}{|c|c|c|c|c|c|c|c|}
\hline & Enrolment & Allocation & \multicolumn{5}{|c|}{ Post-allocation } \\
\hline TIMEPOINT** & $-t_{1}$ & 0 & $\begin{array}{c}\text { Evaluation } \\
t_{1}\end{array}$ & $\begin{array}{c}3 \\
\text { Weeks } \\
t_{2} \\
\end{array}$ & $\begin{array}{c}6 \\
\text { Weeks } \\
t_{3} \\
\end{array}$ & $\begin{array}{c}\text { Discharge } \\
t_{4}\end{array}$ & $\begin{array}{c}6 \text { Months } \\
\text { After } \\
\text { Discharge } \\
t_{5} \\
\end{array}$ \\
\hline \multicolumn{8}{|l|}{ ENROLMENT: } \\
\hline \multirow[t]{2}{*}{ Eligibility screen } & $\mathrm{X}$ & & & & & & \\
\hline & $X$ & & & & & & \\
\hline $\begin{array}{l}\text { Informed consent } \\
\text { Allocation }\end{array}$ & & $\mathrm{X}$ & & & & & \\
\hline \multicolumn{8}{|l|}{ INTERVENTIONS: } \\
\hline \multicolumn{8}{|l|}{ Physical Therapy } \\
\hline \multicolumn{8}{|l|}{$\begin{array}{r}\text { Physical Therapy } \\
+ \text { PEERC }\end{array}$} \\
\hline \multicolumn{8}{|l|}{ ASSESSMENTS: } \\
\hline \multirow{2}{*}{ PCS, OSPRO-ROS } & $\mathrm{X}$ & & & & & & \\
\hline & & & & $x$ & $x$ & $x$ & \\
\hline GRoC & $x$ & & & & & $x$ & \\
\hline TEGNER & $\mathrm{X}$ & & & & $x$ & $x$ & \\
\hline SPADI & $x$ & & $x$ & $X$ & $X$ & $X$ & \\
\hline NPRS & $\mathrm{x}$ & & & $\mathrm{X}$ & $x$ & & \\
\hline \multirow[b]{2}{*}{$\begin{array}{r}\text { MODEMS-S } \\
\text { SANE, } \\
\text { Satisfaction } \\
\text { Rating, Pursuit of } \\
\text { Surgical }\end{array}$} & & & & & & $x$ & \\
\hline & & & & & & & $\mathrm{X}$ \\
\hline
\end{tabular}

\section{Sample Size Estimate}

We powered the study for proportional differences between conditions on decision to have surgery for up to 6 months. Using projections from previous data, and assuming offset inequity between two independent conditions; we modelled power on the following assumptions. In the absence of prior studies, the authors project $30 \%$ of the impairment-based condition only to pursue surgery versus $5 \%$ from the impairment-based plus PEERC condition. This assumes an allocation ratio of $1 / 1$ and error of probability of 0.05 and projected power of $80 \%$. With these assumptions, our projected sample size requires 94 participants. We will employ intention to treat in the primary analysis and do not plan for dropouts.

\section{Statistical Analysis}

We will evaluate descriptive statistics of the two conditions using appropriate parametric and nonparametric tests for differences, depending on the data (continuous or frequency based). For our primary outcome (patient-reported surgery or intention to have surgery), we will measure condition differences in proportions between the impairment-based care only shoulder treatment and the impairment-based care plus PEERC, using a chi-square analysis (or Fisher Exact). 
Table 4 Patient Reported Outcomes Measures Administered in the Study Protocol

\begin{tabular}{|c|c|c|c|c|c|}
\hline Measure & Abbreviation & $\begin{array}{l}\text { Collection Time } \\
\text { point }\end{array}$ & Psychometrics & Construct(s) & Comments \\
\hline $\begin{array}{l}\text { Optimal Screening for } \\
\text { Prediction of Referral and } \\
\text { Outcome [48] }\end{array}$ & OSPRO-ROS & Baseline & $\begin{array}{l}\text { Concurent Validity (pain) } r=0.31 \\
\text { [49] }\end{array}$ & $\begin{array}{l}\text { Comorbidities, } \\
\text { Systemic } \\
\text { Pathology }\end{array}$ & $\begin{array}{l}\text { A review-of-systems screening } \\
\text { tool that includes constructs } \\
\text { associated with comorbidities }\end{array}$ \\
\hline Pain Catastrophizing Scale & PCS & Baseline & ICC $0.92(95 \%$ CI) $[50,51]$ & $\begin{array}{l}\text { Catastrophizing } \\
\text { (rumination, } \\
\text { magnification, } \\
\text { helplessness) }\end{array}$ & $\begin{array}{l}\text { 13-item questionnaire that } \\
\text { assesses the degree to which } \\
\text { individuals have different } \\
\text { thoughts and feelings when } \\
\text { in pain. }\end{array}$ \\
\hline Tegner Activity Scale [52] & TEGNER & $\begin{array}{l}\text { Baseline and } \\
\text { Discharge }\end{array}$ & $\mathrm{ICC}=0.80 \mathrm{MDC}-1.0[36]$ & Function & $\begin{array}{l}\text { Function and activity as a } \\
\text { numerical value between } 0 \\
\text { (complete disability) to } 10 \\
\text { (elite athletics) }\end{array}$ \\
\hline $\begin{array}{l}\text { Shoulder Pain and } \\
\text { Disability Index [29] }\end{array}$ & SPADI & $\begin{array}{l}\text { Baseline, } 6 \text { weeks, } \\
\text { Discharge }\end{array}$ & $\begin{array}{l}\text { ICC }-0.96 \text { [30]CV (Global Disability } \\
\text { Rating) - 0.64[32]MDC- } 21.5 \\
\text { [30]MCID- } 15.4 \text { [31] }\end{array}$ & $\begin{array}{l}\text { Pain and } \\
\text { Function }\end{array}$ & $\begin{array}{l}\text { Assess two domains; a 5-item } \\
\text { subscale that measures pain } \\
\text { and an 8-item subscale that } \\
\text { measures disability }\end{array}$ \\
\hline Numeric Pain Rating Scale & NPRS & $\begin{array}{l}\text { Baseline, } 3 \text { weeks, } \\
6 \text { weeks, } \\
\text { Discharge }\end{array}$ & $\begin{array}{l}\text { IC }-0.88 \text { [34] Excellent Intra-rater } \\
\text { and Interrater reliability with } 100 \% \\
\text { agreement [34]CV (VAS)- } r=0.94 ; \\
95 \% \mathrm{Cl}=0.93-0.95 \text { [35]MCID- } 2.17 \\
\text { [33] }\end{array}$ & Pain & $\begin{array}{l}0 \text { to } 10 \text { ( } 11 \text { point scale) based } \\
\text { on pain intensity with } 0 / 10 \\
\text { representing no pain and } 10 / \\
10 \text { representing the worst } \\
\text { pain possible }\end{array}$ \\
\hline $\begin{array}{l}\text { Musculoskeletal Outcome } \\
\text { Data Evaluation } \\
\text { Management System } \\
\text { [46]'[47]ExpectationsSurvey } \\
\text { \&Satisfaction Survey* }\end{array}$ & $\begin{array}{l}\text { MODEMS- } \\
\text { E MODEMS-S }\end{array}$ & $\begin{array}{l}\text { Expectations: } \\
\text { Enrollment, } 3 \\
\text { weeks, } 6 \\
\text { weeksSatisfaction: } \\
\text { Discharge }\end{array}$ & $\begin{array}{l}\text { Reliability Cohen's kappa } 0.91 \\
\text { [26]Internal consistency } \\
\text { Cronbach's alpha } 0.71 \text { [26] }\end{array}$ & $\begin{array}{l}\text { Patient } \\
\text { Expectations }\end{array}$ & $\begin{array}{l}\text { Likert-based scoring tool with } \\
\text { calculated mean score }\end{array}$ \\
\hline Global Rate of Change [53] & GROC & $\begin{array}{l}3 \text { weeks, } 6 \text { weeks, } \\
\text { Discharge }\end{array}$ & $\begin{array}{l}\text { ICC } 0.9 \text { [41]; face validity between } \\
\text { GRC and patient ratings of the } \\
\text { importance of change (Pearson's } r \\
=0.90 \text { ) [42] and patient } \\
\text { satisfaction measures (Spearman's } \\
\text { rho 0.56-0.70) [43] CR - Shoulder } \\
\text { Disability Questionnaire } r=0.74 \text { ) } \\
\text { [44], NPRS ( } r=0.49 \text { ) [45] }\end{array}$ & $\begin{array}{l}\text { Therapeutic } \\
\text { Outcome }\end{array}$ & $\begin{array}{l}\text { Global rating of change } \\
\text { relative to baseline using a } \\
15 \text {-point ordinal scale (where } \\
-7 \text { is much worse and }+7 \text { is } \\
\text { much better) }\end{array}$ \\
\hline $\begin{array}{l}\text { Single Assessment } \\
\text { Numeric Evaluation [54] }\end{array}$ & SANE & $\begin{array}{l}6 \text { months post } \\
\text { discharge }\end{array}$ & $\begin{array}{l}\text { ICC } 0.84 \text { [39]Correlation with ASES } \\
\text { (Spearman's Rho 0.77) [38]MCID } \\
15 \% \text { [39] }\end{array}$ & Function & $\begin{array}{l}\text { "Please rate your shoulder } \\
\text { function on a scale of } 0 \% \text { (no } \\
\text { function) to } 100 \% \text { (full, } \\
\text { normal function)." }\end{array}$ \\
\hline
\end{tabular}

For our secondary aims, we will use linear mixed effects modelling to compare pain (NPRS and SPADI), function (SPADI, GRoC, TEGNER, and SANE), and follow up expectations and satisfaction (MODEMS) between the two conditions. Linear mixed effects modelling methods are flexible, model individual change, and accommodate for missing data (when present). We will run two analyses, unadjusted and adjusted, in which we will control for all baseline characteristics that are significantly different (if present) and baseline patient expectation, functional outcome, and pain. Pain intensity measures will be evaluated using a negative binomial Poisson, which accounts for count variables with significant skew.

\section{Data Collection and Management}

Study data are managed using REDCap (Research Electronic Data Capture) [56] electronic data capture tools hosted by the study institution. REDCap is a secure, web-based platform designed to provide an interface for validated data capture and export of data to statistical packages. De-identified data, both from the secure electronic medical record as well as paper questionnaires, is entered into the REDCap instrument by study personnel. Ownership of the final dataset rests with the institution.

\section{Monitoring}

Because this investigation presents less than minimal risk or psychosocial harm, an independent data monitoring committee is not required. Adherence to the impairment based treatment intervention will be monitored via checklist for treatment fidelity by non-treating study personnel. To enhance treatment fidelity, the study therapists underwent a formal training program, use a treatment manual to guide their sessions. Participant retention is promoted through contact between the physical therapist and the patient along with participant 
honorarium provided at the initial physical therapy evaluation and at the conclusion of ten weeks of active participation.

\section{Ethics and Financial Support}

This trial has the approval of the Institutional Review Board of Duke University under protocol identification number Pro00088103. Unanticipated problems involving risks to participants or others; information that indicates an adverse change to the risks or potential benefits of the research; or a protocol departure that harmed participants or others or compromises the integrity of the research data require prompt reporting to the institutional review board. This study is externally funded by the Academy of Orthopaedic Physical Therapy. The role of this funding source is solely financial and not influential or contributory to design or interpretation of results. All results from the study will be submitted for publication in peer-reviewed scientific journals. Prior to publication, the authors expect to present the results at professional conferences. For all forms of publication, the authors must meet the four tenets of authorship set forth by the International Committee of Medical Journal Editors. The authors declare no competing interests.

\section{Discussion}

This trial aims to measure effects of a novel PEERC intervention designed to change expectations of conservative care. In the primary analysis, the efficacy of PEERC will be assessed via participant report of their having had or have the intent to have surgery 6 months after finishing impairment-based care. In secondary analyses we will also investigate the effect of PEERC on pain, function, expectations and satisfaction with conservative care. Reliance on patient reported outcome measures, because they often lack evidence of validity, is a recognized limitation of clinical trials. Our primary outcome, pursuance of surgery, is no exception. The medical record can be queried, but this would only serve to verify the presence, not the absence, of planned or performed surgery because the patient may seek care outside of the study institution.

When considering the management decisions for RCRSP, clinicians, policy makers, and patients are faced with an intriguing dilemma. Despite higher risks/harms with surgical treatments, conservative treatments have similar outcomes [1-4]. The comparable results may be a reflection of a dedicated focus toward a biomedically oriented strategy [57]. Patient expectations (outside the biomedically oriented mechanisms associated with conservative and non-conservative treatment approaches) may also influence functional outcomes and the decision to pursue additional care options. This assumption is supported by studies that have identified the prognostic role of patient expectations across a variety of conservative and non-conservative care options $[47,58]$.

A patient-centered approach emphasizes patients' treatment expectations - i.e. their desires, thoughts, and beliefs about treatment and its outcome [59]. Patientcentered models of care allow patients more control in directing their treatment and are a viable alternative method of enhancing treatment outcomes [60]. No studies of RCRSP have investigated the influence of brief, theory-based interventions for changing expectations about what treatment is appropriate/optimal when evidence suggests there is not an obvious choice based on superiority. Our study will focus on addressing patient expectations to understand that a conservative approach will provide a similar outcome to surgery, without unnecessary risks.

Despite recognition that patient expectations has a role in influencing functional outcomes and the decision to pursue surgical care in patients with RCRSP [8-10], there have been few studies designed to test interventions designed to change expectations $[15,16]$. Research has shown that the best predictor of functional outcomes with a conservative approach are pre-treatment, patient expectations [15, 61]. Expectations (i.e. attitudes, thoughts, and beliefs) are malleable using methods rooted in cognitive-behavioral science that focus on education, engagement and cognitive restructuring.

If this innovative PEERC intervention is successful, the approach may provide the appropriate foundations that could be applied to other musculoskeletal disorders where there are viable conservative options to surgical care.

\section{Trial Status}

Recruitment of participants began on September 18, 2018 and currently continues. Completion is anticipated at the conclusion of 2021. The final decision to terminate the trial rests with the primary investigator.

\section{Abbreviations \\ PEERC: Patient Engagement Education and Restructuring of Cognitions; CBT: Cognitive Behavioral Therapy; RCRSP: Rotator Cuff Related Shoulder Pain; MODEMS: Musculoskeletal Outcome Data Evaluation Management System; SPADI: Shoulder Pain and Dysfunction Index; OSPRO-ROS: Optimal Screening Prediction of Referral and Outcome; PCS: Pain Catastrophizing Scale; SANE: Single Assessment Numeric Evaluation; TEGNER: Tegner Activity Scale; NPRS: Numeric Pain Rating Scale; VAS: Visual Analog Scale; \\ GRoC: Global Rate of Change}

\section{Acknowledgements}

Not Applicable.

\section{Authors' contributions}

Conception and design: CC, HM, Critical revision for important intellectual content CC, FK, SZG, Drafting the manuscript HM, CC, Authors' approval of the manuscript. CC, HM, SZG, FK, CM, JK, ADL, Data collection and analysis $\mathrm{CC}, \mathrm{HM}, \mathrm{CM}, \mathrm{JK}, \mathrm{ADL}$. 


\section{Funding}

This study is externally funded by the Academy of Orthopaedic Physical Therapy. The role of this funding source is solely financial and not influential or contributory to design or interpretation of results.

\section{Availability of data and materials} Not applicable.

\section{Declarations}

\section{Ethics approval and consent to participate}

This trial has the approval of the Institutional Review Board of Duke University under protocol identification number Pro00088103. Study activities are not initiated until the patient provides written consent.

\section{Consent for publication}

Not applicable.

\section{Competing interests}

The authors declare that they have no competing interests.

\section{Author details}

${ }^{1}$ Physical Therapist, Urbaniak Sports Sciences Institute, Duke University Health System, 3475 Erwin Rd, Durham, NC 27705, USA. ²Professor in Psychiatry and Behavioral Sciences, Psychology and Neuroscience, Medicine, and Anesthesiology, 2200 W Main St, Suite 340, Durham, NC 27705, USA. ${ }^{3}$ Laszlo Ormandy Distinguished Professor, Department of Orthopaedic Surgery, Duke Clinical Research Institute, 200 Morris Street, Durham, NC 27701, USA ${ }^{4}$ Professor, Director of Clinical Research Facilitation, Duke Doctor of Physical Therapy Division, Duke Clinical Research Institute, 311 Trent Drive, Durham, NC 27705, USA.

Received: 6 May 2021 Accepted: 4 August 2021 Published online: 24 August 2021

\section{References}

1. Dalton SE. The conservative management of rotator cuff disorders. $\mathrm{Br} \mathrm{J}$ Rheumatol. 1994;33(7):663-7.

2. Goldberg BA, Nowinski RJ, Matsen FA. Outcome of nonoperative management of full-thickness rotator cuff tears. Clin Orthop Relat Res. 2001; 382:99-107.

3. Kukkonen J, Joukainen A, Lehtinen J, Mattila KT, Tuominen EKJ, Kauko T, et al. Treatment of non-traumatic rotator cuff tears: A randomised controlled trial with one-year clinical results. Bone Joint J. 2014;96-B(1):75-81.

4. Moosmayer S, Lund G, Seljom U, Svege I, Hennig T, Tariq R, et al. Comparison between surgery and physiotherapy in the treatment of small and medium-sized tears of the rotator cuff: A randomised controlled study of 103 patients with one-year follow-up. J Bone Joint Surg Br. 2010;92(1):83-91.

5. lyengar JJ, Samagh SP, Schairer W, Singh G, Valone FH, Feeley BT. Current trends in rotator cuff repair: surgical technique, setting, and cost. Arthroscopy. 2014;30(3):284-8.

6. Colvin AC, Egorova N, Harrison AK, Moskowitz A, Flatow EL. National trends in rotator cuff repair. J Bone Joint Surg Am. 2012;94(3):227-33.

7. Fermont AJM, Wolterbeek N, Wessel RN, Baeyens J-P, de Bie RA. Prognostic factors for successful recovery after arthroscopic rotator cuff repair: a systematic literature review. J Orthop Sports Phys Ther. 2014;44(3):153-63.

8. Henn RF, Kang L, Tashjian RZ, Green A. Patients' preoperative expectations predict the outcome of rotator cuff repair. J Bone Joint Surg Am. 2007;89(9): 1913-9.

9. O'Malley KJ, Roddey TS, Gartsman GM, Cook KF. Outcome expectancies, functional outcomes, and expectancy fulfillment for patients with shoulder problems. Med Care. 2004;42(2):139-46.

10. Skatteboe S, Røe C, Fagerland MW, Granan L-P. Expectations of pain and functioning in patients with musculoskeletal disorders: a cross-sectional study. BMC Musculoskelet Disord. 2017;18(1):48.

11. Bishop MD, Mintken PE, Bialosky JE, Cleland JA. Patient expectations of benefit from interventions for neck pain and resulting influence on outcomes. J Orthop Sports Phys Ther. 2013;43(7):457-65.

12. Cormier $S$, Lavigne $G L$, Choinière $M$, Rainville $P$. Expectations predict chronic pain treatment outcomes. Pain. 2016;157(2):329-38.
13. Ellis DJ, Mallozzi SS, Mathews JE, Moss IL, Ouellet JA, Jarzem P, et al. The Relationship between Preoperative Expectations and the Short-Term Postoperative Satisfaction and Functional Outcome in Lumbar Spine Surgery: A Systematic Review. Global Spine J. 2015;5(5):436-52.

14. Kongsted A, Vach W, Axø M, Bech RN, Hestbaek L. Expectation of recovery from low back pain: a longitudinal cohort study investigating patient characteristics related to expectations and the association between expectations and 3-month outcome. Spine. 2014;39(1):81-90.

15. Riley SP, Bialosky J, Cote MP, Swanson BT, Tafuto V, Sizer PS, et al. Thoracic spinal manipulation for musculoskeletal shoulder pain: Can an instructional set change patient expectation and outcome? Man Ther. 2015;20(3):469-74.

16. Martínez-Cervera FV, Olteanu TE, Gil-Martínez A, Díaz-Pulido B, Ferrer-Peña R Influence of expectations plus mobilization with movement in patient with lateral epicondylalgia: a pilot randomized controlled trial. J Exerc Rehabil. 2017;13(1):101-9.

17. Loudon K, Treweek S, Sullivan F, Donnan P, Thorpe KE, Zwarenstein M. The PRECIS-2 tool: designing trials that are fit for purpose. BMJ. 2015;8:350: h2147.

18. Loudon K, Zwarenstein M, Sullivan FM, Donnan PT, Gágyor I, Hobbelen HJSM, et al. The PRECIS-2 tool has good interrater reliability and modest discriminant validity. J Clin Epidemiol. 2017:88:113-21.

19. Institute of Medicine (US) Committee on Strategies for Small-NumberParticipant Clinical Research Trials. Small clinical trials: issues and challenges. Evans CH, Ildstad ST, editors. Washington (DC): National Academies Press (US); 2001.

20. Temple R, Ellenberg SS. Placebo-controlled trials and active-control trials in the evaluation of new treatments. Part 1: ethical and scientific issues. Ann Intern Med. 2000;133(6):455-63.

21. Schulz KF, Altman DG, Moher D. CONSORT 2010 statement: Updated guidelines for reporting parallel group randomised trials. J Pharmacol Pharmacother. 2010;1(2):100-7.

22. Hoffmann TC, Glasziou PP, Boutron I, Milne R, Perera R, Moher D, et al. Better reporting of interventions: template for intervention description and replication (TIDieR) checklist and guide. BMJ. 2014;348:g1687.

23. Kuhn JE. Exercise in the treatment of rotator cuff impingement: a systematic review and a synthesized evidence-based rehabilitation protocol. J Shoulder Elbow Surg. 2009;18(1):138-60.

24. Garrison JC, Shanley E, Thigpen C, Hegedus E, Cook C. Between-session changes predict overall perception of improvement but not functional improvement in patients with shoulder impingement syndrome seen for physical therapy: an observational study. Physiother Theory Pract. 2011;27(2): 137-45.

25. Stevenson K, Jackson S, Shufflebotham J, Roddy E, Foster NE. Development and delivery of a physiotherapist-led exercise intervention in a randomised controlled trial for subacromial impingement syndrome (the SUPPORT trial). Physiotherapy. 2017;103(4):379-86.

26. Zywiel MG, Mahomed A, Gandhi R, Perruccio AV, Mahomed NN. Measuring expectations in orthopaedic surgery: a systematic review. Clin Orthop Relat Res. 2013:471(11):3446-56.

27. Glance LG, Osler TM, Neuman MD. Redesigning surgical decision making for high-risk patients. N Engl J Med. 2014;370(15):1379-81.

28. Torrens C, Miquel J, Santana F. Do we really allow patient decision-making in rotator cuff surgery? A prospective randomized study. J Orthop Surg Res. 2019;14(1):116.

29. Breckenridge JD, McAuley JH. Shoulder pain and disability index (SPADI). J Physiother. 2011;57(3):197.

30. Roddey TS, Olson SL, Cook KF, Gartsman GM, Hanten W. Comparison of the University of California-Los Angeles Shoulder Scale and the Simple Shoulder Test with the shoulder pain and disability index: single-administration reliability and validity. Phys Ther. 2000;80(8):759-68.

31. Ekeberg OM, Bautz-Holter E, Tveitå EK, Keller A, Juel NG, Brox Jl. Agreement, reliability and validity in 3 shoulder questionnaires in patients with rotator cuff disease. BMC Musculoskelet Disord. 2008;9:68.

32. Schmitt J, Di Fabio RP. The validity of prospective and retrospective global change criterion measures. Arch Phys Med Rehabil. 2005;86(12): 2270-6.

33. Michener LA, Snyder AR, Leggin BG. Responsiveness of the numeric pain rating scale in patients with shoulder pain and the effect of surgical status. Sport Rehabil. 2011;20(1):115-28.

34. Herr KA, Spratt K, Mobily PR, Richardson G. Pain intensity assessment in older adults: use of experimental pain to compare psychometric properties 
and usability of selected pain scales with younger adults. Clin J Pain. 2004 20(4):207-19.

35. Bijur PE, Latimer $\mathrm{CT}$, Gallagher EJ. Validation of a verbally administered numerical rating scale of acute pain for use in the emergency department. Acad Emerg Med. 2003;10(4):390-2.

36. Briggs KK, Lysholm J, Tegner Y, Rodkey WG, Kocher MS, Steadman JR. The reliability, validity, and responsiveness of the Lysholm score and Tegner activity scale for anterior cruciate ligament injuries of the knee: 25 years later. Am J Sports Med. 2009;37(5):890-7.

37. Williams JW, Holleman DR, Simel DL. Measuring shoulder function with the Shoulder Pain and Disability Index. J Rheumatol. 1995;22(4):727-32.

38. Wickman JR, Lau BC, Scribani MB, Wittstein JR. Single Assessment Numeric Evaluation (SANE) correlates with American Shoulder and Elbow Surgeons score and Western Ontario Rotator Cuff index in patients undergoing arthroscopic rotator cuff repair. J Shoulder Elbow Surg. 2020;29(2):363-9.

39. Thigpen CA, Shanley E, Momaya AM, Kissenberth MJ, Tolan SJ, Tokish JM, et al. Validity and Responsiveness of the Single Alpha-numeric Evaluation for Shoulder Patients. Am J Sports Med. 2018;46(14):3480-5.

40. Kamper SJ, Maher CG, Mackay G. Global rating of change scales: a review of strengths and weaknesses and considerations for design. J Man Manip Ther. 2009;17(3):163-70.

41. Costa LOP, Maher CG, Latimer J, Ferreira PH, Ferreira ML, Pozzi GC, et al. Clinimetric testing of three self-report outcome measures for low back pain patients in Brazil: which one is the best? Spine. 2008;33(22):2459-63.

42. Watson CJ, Propps M, Ratner J, Zeigler DL, Horton P, Smith SS. Reliability and responsiveness of the lower extremity functional scale and the anterior knee pain scale in patients with anterior knee pain. J Orthop Sports Phys Ther. 2005;35(3):136-46.

43. Fischer D, Stewart AL, Bloch DA, Lorig K, Laurent D, Holman H. Capturing the patient's view of change as a clinical outcome measure. JAMA. 1999; 29(12):1157-62. 282(.

44. van der Windt DA, van der Heijden GJ, de Winter AF, Koes BW, Devillé W, Bouter LM. The responsiveness of the Shoulder Disability Questionnaire. Ann Rheum Dis. 1998;57(2):82-7.

45. Stewart M, Maher CG, Refshauge KM, Bogduk N, Nicholas M. Responsiveness of pain and disability measures for chronic whiplash. Spine. 2007;32(5)(1): 580-5.

46. Soroceanu A, Ching A, Abdu W, McGuire K. Relationship between preoperative expectations, satisfaction, and functional outcomes in patients undergoing lumbar and cervical spine surgery: a multicenter study. Spine. 2012;37(2):E103-8

47. Tashjian RZ, Bradley MP, Tocci S, Rey J, Henn RF, Green A. Factors influencing patient satisfaction after rotator cuff repair. J Shoulder Elbow Surg. 2007;16(6):752-8.

48. George SZ, Beneciuk JM, Lentz TA, Wu SS, Dai Y, Bialosky JE, et al. Optimal screening for prediction of referral and outcome (OSPRO) for musculoskeletal pain conditions: results from the validation cohort. J Orthop Sports Phys Ther. 2018:48(6):460-75

49. George SZ, Beneciuk JM, Bialosky JE, Lentz TA, Zeppieri G, Pei Q, et al. Development of a Review-of-Systems Screening Tool for Orthopaedic Physical Therapists: Results From the Optimal Screening for Prediction of Referral and Outcome (OSPRO) Cohort. J Orthop Sports Phys Ther. 2015; 45(7):512-26.

50. Osman A, Barrios FX, Gutierrez PM, Kopper BA, Merrifield T, Grittmann L. The Pain Catastrophizing Scale: further psychometric evaluation with adult samples. J Behav Med. 2000;23(4):351-65.

51. Sullivan MJL, Bishop SR, Pivik J. The Pain Catastrophizing Scale: Development and validation. Psychol Assess. 1995;7(4):524-32.

52. Briggs KK, Kocher MS, Rodkey WG, Steadman JR. Reliability, validity, and responsiveness of the Lysholm knee score and Tegner activity scale for patients with meniscal injury of the knee. J Bone Joint Surg Am. 2006;88(4): 698-705.

53. Kamper S. Global Rating of Change scales. Aust J Physiother. 2009;55(4):289.

54. Williams GN, Gangel TJ, Arciero RA, Uhorchak JM, Taylor DC. Comparison of the Single Assessment Numeric Evaluation method and two shoulder rating scales. Outcomes measures after shoulder surgery. Am J Sports Med. 1999; 27(2):214-21.

55. George SZ, Beneciuk JM, Lentz TA, Wu SS. The Optimal Screening for Prediction of Referral and Outcome (OSPRO) in patients with musculoskeletal pain conditions: a longitudinal validation cohort from the USA. BMJ Open. 2017;7(6).
56. Harris PA, Taylor R, Thielke R, Payne J, Gonzalez N, Conde JG. Research electronic data capture (REDCap)--a metadata-driven methodology and workflow process for providing translational research informatics support. J Biomed Inform. 2009:42(2):377-81.

57. Main CJ, George SZ. Psychologically informed practice for management of low back pain: future directions in practice and research. Phys Ther. 2011; 91(5):820-4.

58. Dunn WR, Kuhn JE, Sanders R, An Q, Baumgarten KM, Bishop JY, et al. 2013 Neer Award: predictors of failure of nonoperative treatment of chronic, symptomatic, full-thickness rotator cuff tears. J Shoulder Elbow Surg. 2016; 25(8):1303-11.

59. Zeppieri G, George SZ. Patient-defined desired outcome, success criteria, and expectation in outpatient physical therapy: a longitudinal assessment. Health Qual Life Outcomes. 2017;15(1):29.

60. Brown JL, Edwards PS, Atchison JW, Lafayette-Lucey A, Wittmer VT, Robinson ME. Defining patient-centered, multidimensional success criteria for treatment of chronic spine pain. Pain Med. 2008;9(7):851-62.

61. Chester R, Shepstone L, Daniell H, Sweeting D, Lewis J, Jerosch-Herold C. Predicting response to physiotherapy treatment for musculoskeletal shoulder pain: a systematic review. BMC Musculoskelet Disord. 2013;14:203.

\section{Publisher's Note}

Springer Nature remains neutral with regard to jurisdictional claims in published maps and institutional affiliations.
Ready to submit your research? Choose BMC and benefit from:

- fast, convenient online submission

- thorough peer review by experienced researchers in your field

- rapid publication on acceptance

- support for research data, including large and complex data types

- gold Open Access which fosters wider collaboration and increased citations

- maximum visibility for your research: over $100 \mathrm{M}$ website views per year

At BMC, research is always in progress.

Learn more biomedcentral.com/submissions 